\title{
DISCUSSÕES INICIAIS SOBRE LESBIANIDADES E EDUCAÇÃO ESCOLAR
}

\author{
BRAGA, Keith Daiani da Silva ${ }^{1}$ \\ RIBEIRO, Arilda Ines Miranda² \\ CAETANO, Márcio Rodrigo Vale ${ }^{3}$
}

\section{RESUMO}

A temática da sexualidade, em especial, da "diversidade sexual" no campo da Educação tem sido na última década bastante explorada em trabalhos acadêmicos brasileiros. Entretanto, parte muitíssimo pequena de tais pesquisas tem como eixo central as experiências de mulheres lésbicas. Nosso texto se localiza deste modo, numa tentativa de abordar este tema pouco visibilizado, por meio da apresentação das reflexões iniciais de nossa pesquisa de doutorado em andamento, na qual nos propomos trabalhar com as experiências escolares de lésbicas egressas da escola pública. Como se trata de uma investigação em fase inicial, os resultados parciais aqui explorados dizem respeito ao levantamento bibliográfico que tem sustentado nossa proposta. Por meio dele, evocamos ao longo do artigo: os estudos sobre lesbianidades, a questão da visibilidade e, por fim, a lesbofobia nas instituições de ensino.

PaLAVRAS-CHAVE: Lesbianidades - Educação Escolar - Levantamento bibliográfico.

\section{ABSTRACT}

The sexuality as a thematic of study, in particular, the "sexual diversity" in the field of Education has been large explored in the last decade in Brazilian academic works. However, a very small part of such research's centered on the experiences of lesbian women. Our text is based in this way, in an attempt to approach this subject that is not very visible, through the presentation of the initial reflections of our in progress doctoral research, in which we propose to work with the school experiences of lesbians from the public school. As it is an investigation in the initial phase, the partial results presented here concern the bibliographical survey that has sustained our proposal. Through it, we recall throughout the article: studies on lesbianities, the question of visibility and, finally, lesbophobia at educational institutions.

KeYWORDS: Lesbianities - School Education - Bibliographic survey.

\footnotetext{
${ }^{1}$ Doutoranda do Programa de Pós-Graduação em Educação da FCT/UNESP. Email: keith_daiani@hotmail.com

${ }^{2}$ Professora da Faculdade de Ciências e Tecnologia da Universidade Estadual Júlio de Mesquita Filho (UNESP). Email: arilda@fct.unesp.br

${ }^{3}$ Professor da Faculdade de Educação da FURG. Email: marciocaetano@furg.br
} 


\section{INTRODUÇÃO}

Este trabalho tem por objetivo apresentar as discussões iniciais do projeto de doutorado em andamento intitulado "Lesbianidades, performatizações de gênero e educação escolar", que é desenvolvido no Programa de Pós-Graduação em Educação da Faculdade de Ciências e Tecnologia da Universidade Estadual Paulista "Júlio de Mesquita Filho".

A pesquisa consiste em compreender como lésbicas egressas do Ensino Médio público vivenciaram as amizades, identidades, sociabilidades e sexualidades em suas trajetórias escolares; os contextos de invisibilidade e de hipervisibilidade experimentados nas instituições de ensino onde estudaram; a lesbofobia existente no ambiente da escola, enquanto técnica de "ensino" e conformação de meninas na norma heterossexual; e, por fim, as resistências criadas por elas para escapar ou confrontar o padrão de sexualidade hegemônico.

Para desenvolver esta investigação partimos de uma concepção metodológica qualitativa vinculada aos estudos de gênero e sexualidade, a partir de realização de entrevistas e orientação teórica voltada para autoras e autores ligados aos Estudos Pós-Estruturalistas, Feministas e Queer. Como se trata de uma pesquisa em fase inicial, nossos resultados parciais expostos ao longo do texto dizem respeito ao levantamento bibliográfico que vem sustentando até então nossa proposta.

No sentido de melhor apresentarmos nossa argumentação dividimos o artigo em três partes: na primeira abordamos a pouca centralidade que é dada as lesbianidades nos debates de gênero e sexualidade, em seguida falamos a respeito das lesbianidades hipervisíveis a partir do conceito de masculinidade feminina e, por último, discutimos rapidamente a lesbofobia na escola. Encerramos, assim, nas considerações seguidas das referências bibliográficas.

\section{A QUESTÃO DA CARÊNCIA DE VISIBILIDADE DO TEMA DAS LESBIANIDADES}

Um dos principais motivos de termos nos interessado por uma investigação científica em que o ponto central - que possibilita a problematização de gênero e sexualidade no espaço da escola - são os relatos das lésbicas é porque inegavelmente as experiências escolares destes sujeitos tem sido muito pouco trazidas para o debate acadêmico, mesmo em tempos de crescente exploração do tema da sexualidade, mais especificamente "diversidade sexual", no campo da Educação em pesquisas e publicações brasileiras.

Dito de outro modo: ainda que a intensificação destes temas, em especial com a publicação do "Brasil sem Homofobia: programa de combate à violência e à discriminação contra $\mathrm{GLBT}^{4} \mathrm{e}$ promoção da cidadania homossexual - $\mathrm{BSH}^{5}$ (BRASIL, 2004)", seja notória e com importantes contribuições, parte muitíssimo pequena de tais pesquisas não são centralizadas unicamente em sujeitos gays. O que nos provoca a pensar se as apropriações conceituais, bem como, as problematizações que temos, por exemplo, para criticar a homofobia nas escolas dão conta de questionar também a misoginia, lesbofobia, machismo e sexismo nesses espaços educativos.

Barbosa e Facchini (2006) nos mostram que a produção de conhecimento científico sobre as mulheres lésbicas, fora

4 Devido às deliberações tomadas durante a $1^{\mathrm{a}}$. Conferência Nacional GLBT em 2008, a sigla do movimento passou a ser nomeada de Lésbicas, Gays, Bissexuais, Travestis e Transexuais (LGBT). A alteração buscou visibilizar as mulheres lésbicas.

\footnotetext{
${ }^{5}$ A coordenação do Programa Brasil Sem Homofobia (BSH) é desenvolvida pela Secretaria Especial de Direitos Humanos (SDH) e suas ações têm como eixo central envolver todos os Ministérios e Secretarias do Governo Federal com vista a promover, a partir do reconhecimento das sequelas ocasionadas com a discriminação, a cidadania da população LGBT por meio de políticas públicas.
} 
de um viés patologizante, iniciou-se apenas a partir de 1980. No levantamento desses estudos, realizado por Toledo (2008), foram encontrados, de 1980 a 2008, vinte e cinco pesquisas, nenhuma da área da Educação. Em nossa busca, de 2008 a 2015, identificamos vinte e nove trabalhos defendidos, dos quais somente quatro são do campo da Educação: Cavalero (2009), Oliveira (2010), Fortes (2013) e Maciel (2014).

Em consonância com autoras feministas, como Espinosa (2007), Gimeno (2010) e Crawford (2012), pensamos que este quadro precário está ligado à tendência das propostas investigativas de questionamento da heterossexualidade obrigatória $^{6}$, que se dizem "gerais", de fato tomarem como referência a experiência gay. Assim, seguem sutilmente como afirma Françoise Guillemaut (1994, p. 228) associando "[...] O homossexual com a figura universal da homossexualidade, as lésbicas expressões particulares, marginais" (tradução nossa). As lesbianidades são relegadas a uma minoria flutuante dentro da minoria (RASINES, 2010).

Com frequência, o argumento trazido para explicar essa carência de visibilidade das lesbianidades, além da questão do próprio silenciamento histórico imposto às mulheres (SWAIN, 2000; PERROT, 2009), refere-se aos efeitos da heterossexualidade presumida em decorrência das performances de gênero próximas dos padrões hegemônicos de feminilidade (BUTLER, 2003; WILTON, 2003; BORRIL-

\footnotetext{
6 Algumas feministas como Espinosa (2007) e Falquet $(2009 ; 2014)$ interrogam, porque conceitos, como "heterossexualidade obrigatória" e "pensamento heterossexual" nascidos de reflexões feministas lésbicas de Adrienne Rich (1980) e Monique Wittig (1980) utilizados como base para a ideia de heteronormatividade, atualmente são incorporados em vertentes teóricas como Teoria Queer para analisar primordialmente transgressões de homens gays ou sujeitos "trans", mas não são em mesma medida operacionalizados para analisar as potências e subversões lésbicas.
}

LO, 2010).

Em outras palavras, por existir esse equívoco de estabelecer uma continuidade entre a identidade e o desejo, numa relação de causa, a "coerência" das performatizações de gênero das mulheres tende a invalidar a possibilidade de homossexualidade (GUILLEMAUT, 1994; BENTO, 2011; BRANDÃO, 2015). Essa lógica possui ainda mais força por os sujeitos em questão não serem homens, pois numa sociedade historicamente centrada no masculino como eixo da existência, a sexualidade da mulher é presumida como propriedade do homem (LAURETIS, 1994), e isso impacta também no sentido de que paira uma espécie de "cegueira", menosprezo para as afetividades e/ou práticas sexuais ausentes de falo.

Todavia, em consonância com Borrillo (2010), Junqueira (2012) e Dinis (2014) colocamos em suspenso qualquer tipo de interpretação, a partir desta "indiferença" sobre as dissidências femininas, em termos de maior respeito e aceitação, principalmente quando estamos discutindo as experiências escolares, tendo em vista que as instituições de ensino atuam como auxiliadoras poderosas na produção de masculinidades e feminilidades alinhadas a heterossexualidade. Assim, desconfiamos com Caetano (2011) das afirmações que propõe desinteresse da escola sobre o tema da sexualidade. Também não cremos que alunas não-heterossexuais estejam livres dos investimentos, vigilância e até mesmo exposição a situações de violência física e verbal nos espaços educativos.

\section{MAS TODA LÉSBICA É INVISÍVEL?}

Outro ponto muito importante sobre a questão da visibilidade das lesbianidades diz respeito ao perigo que há em aderir de imediato o discurso de que as lésbicas são: primeiro, imperceptíveis, invisíveis, desconsideradas e, segundo, em decorrência disso, menos alvo de violência, pois, além do que já expomos acima 
sobre o menor destaque não ser sinônimo de aceitação, essa perspectiva leva a homogeneização e supressão de outras vivências lesbianas.

\section{Com Viñuales (2002), Espinosa (2007), Halberstam (2008), Gimeno} (2010) e Platero (2009a; 2013) acreditamos que existem inúmeras maneiras de se viver as lesbianidades, que se alteram e formam outras possibilidades ao se articularem com marcações como raça/etnia, classe social, geração e masculinidade, tornando assim totalmente imprudente que estas sejam generalizadas em presumidos contextos de ocultação.

Nessa mesma direção, Halberstam (2008) em sua obra "Masculinidad Femenina" traz diálogos e ideias de Anna Marie Smith, Evelynn Hammonds e Marilyn Frye que afirmam os riscos de determinados discursos silenciarem muitas lésbicas: negras, butchs, masculinas trabalhadoras de classes baixas, presidiárias entre outras que, ao contrário do que se supõe, vivem uma hipervisibilidade que às expõem, inclusive, às diversas violências e repreensões. Deste modo, nas palavras da autora: "[...] hay distintos silencios y diferentes formas de invisibilidad en relacion a diferentes cuerpos lesbianos, y mientras que algunas lesbianas se sienten rodeadas de silencio, otras se sienten demasiado mostradas e hipervisibles" (HALBERSTAM, 2008, p. 139).

Em nossa pesquisa, ao trabaIharmos com as experiências escolares de participantes que se autodefinem como dykes, bucths, caminhoneiras, sapatas, bofinhos, entre outros termos atrelados à ideia de hipervisibilidade lesbiana, abordaremos o conceito de masculinidade feminina de Halberstam, que, grosso modo, refere-se a uma masculinidade sem ho-

7 Halberstam (2008) define butchs como: as lésbicas que se sentem confortáveis e se identificam com vestimenta, adereços, estilos e códigos considerados masculinos. mens, alternativa à hegemônica, produzida no corpo das mulheres. O trânsito de gênero, que permite a performance masculina não é entendida nessa perspectiva como exclusividade de transhomens, FTM's (female to male) e transgêneros. Lésbicas e mulheres heterossexuais também podem se constituir em desacordo com os códigos de feminilidade sem necessariamente desejarem mudar de sexo ou sentirem uma sensação profunda de pertencimento "ao corpo errado", frequentes nas experiências trans.

No desenvolvimento desse conceito, Halberstam (2008) nos explica que as variações na performatização do gênero no corpo das meninas só é mais tolerada, em relação à desempenhada em meninos, durante a infância, já que na passagem para a adolescência são exercidas também sobre elas forças contínuas de reeducação. Para Britzman (1996) isso repousa na crença de que para ter a sexualidade "correta" é pré-requisito desenvolver o gênero adequado. Assim, o processo de (re) feminizá-las tem o intuito de garantir o desejo heterossexual e eliminar a ameaça da lesbianidade (HALBERSTAM, 2008). Por conta disso que a autora Berenice Bento em entrevista à Dias (2014) afirma não acreditar que a homossexualidade tenha sido totalmente despatologizada, pois é por meio das regulações intensas de gênero e pela brecha da "disforia de gênero" ${ }^{8}$ que se seguem, seja em clínicas, famílias ou mesmo escolas, tentando preveni-la ou mesmo curá-la.

Masculinidade feminina ou, no caso a masculinidade lesbiana ao ser empreendida em nosso estudo abre possibilidades

\footnotetext{
8 "Disforia de gênero" é um termo médico para designar um estado patológico de não conformação com o gênero atribuído ao nascimento. Está catalogado CID-10 Cadastro Internacional de Doenças como "Transtorno de Identidade de Gênero" seguido em vários países, incluindo o Brasil, no qual a transexualidade ainda não é vista como forma saudável de viver a identidade e sexualidade.
} 
de enriquecer a problematização das negociações, tensões, violências e resistências produzidas no ambiente da escola, quando os corpos dissidentes, no que tange a performatização de gênero e desejo, são de mulheres. Nossa investigação, intenta deste modo fazer aproximações novas que de algum modo possam contribuir com os debates já existentes sobre gênero e sexualidade na Educação. Dado que sobre este aspecto em especifico, temos os estudos que discutem masculinidades na escola, atrelados quase que exclusivamente às vivências de meninos, bem como, quando se considera as transgressões privilegiam as experiências de sujeitos que passam do masculino para o feminino, raramente o inverso (HALBERSTAM, 2008; PLATERO, 2009a, 2009b).

\section{A LESBOFOBIA NA ESCOLA}

No intento de alcançar uma ampliação teórica, pretendemos olhar para as narrativas escolares de nossas participantes que versarem sobre situações de preconceito e hostilizações em suas trajetórias escolares, também com o emprego da lesbofobia, outra acepção pouco discutida e utilizada.

Esta funcionará enquanto auxiliar da crítica geral empreendida pelo conceito de homofobia. Manteremos essa conexão, por acreditarmos, em consonância com Gayle Rubin (1989, p. 54) que não devemos restringir a análise da situação das lésbicas em termos de opressão as mulheres:

[...] las lesbianas son también oprimidas en su calidad de homosexuales y pervertidas, debido a la estratificación sexual, no de géneros" o que as faz compartilhar "[...] muchos de los rasgos sociológicos y muchos de los castigos sociales con los varones gay, los sadomasoquistas, los travestidos y las prostitutas.
Com efeito, as autoras Viñuales (2002), Gimeno (2010), Platero (2010) e Crawford (2012) nos permitem pensar a lesbofobia como o cruzamento da misoginia e sexismo com a homofobia. Esta produz contextos específicos de vulnerabilidades, onde se situam desde as violências brutais como assassinatos, estupros "corretivos" e assédios sexuais até as hostilizações verbais, micro-punições, vigilâncias sutis, movimentos restritivos de controle, (re) educação e adequação às normas, que expõem não só as dissidentes sexuais, mas também todas as mulheres - mesmo as heterossexuais - não enquadradas nos modelos hegemônicos de feminilidade ou alinhadas às formas de masculinidades femininas.

O uso do termo lesbofobia também se coloca como importante, porque quando evocamos somente homofobia, corremos o risco de não apreender as especificidades e formas menos explícitas de a heteronormatividade agir para com as outras dissidências, no nosso caso a lesbiana, mas também há, por exemplo, as travestilidades e transsexualidades, que nos convocam a falar da brutalidade que é a transfobia.

Ademais, pensando em instituições de ensino e na Educação, Rogerio Junqueira $(2012$, p. 294) faz um relato interessante:

[...] Durante esses anos de encontros com profissionais da educação de todo o país, algo que me chamou a atenção foi o fato de a maior parte dos relatos docentes referirem-se a casos de heterossexismo e homofobia quase que apenas contra estudantes do sexo masculino.

A nosso ver, ainda que, em certa medida, a dissidência sexual de meninos seja mais punida e repudiada na esfera pública, em decorrência da homofobia ser um dos elementos constitutivos da mascu- 
linidade hegemônica, temos que considerar também os impactos que a massificação do conceito de homofobia ${ }^{9}$ gerou, inclusive nos sujeitos que atuam na escola, que a sintetizam como "o ódio contra gays", tornando-os "cegos" ou coniventes com suas formas, mais silenciosas, de violentar e adequar meninas na heterossexualidade.

Michael Bochenek e Widney Brown (2001) realizaram uma ampla pesquisa denominada "Hatred In The Hallways: Violence And Discrimination Against Lesbian, Gay, Bisexual, And Transgender Students In U.S. Schools" na qual discutem os contextos, práticas e hostilização e vulnerabilidades vividas por estudantes não heterossexuais. Em relação às experiências de garotas lésbicas os autores pontuam que, no entrelaçamento de sexismo e homofobia, são produzidas variadas for-

\footnotetext{
${ }^{9}$ No Brasil, a palavra "homofobia" passou a ganhar maior visibilidade em 2001, com a criação do Projeto de Lei Complementar no 5003/2001 que criminaliza a violência homofóbica em âmbito nacional, conhecido atualmente como "PL 122". No mesmo ano, no Estado de São Paulo foi criada e promulgada a Lei Estadual 10.948 que pune "[...] toda manifestação atentatória ou discriminatória praticada contra cidadão homossexual, bissexual ou transgênero" (ESTADO DE SÃO PAULO, 2001). Já em 2004, o destaque se acentuou com o lançamento do programa "Brasil sem Homofobia" pelo Governo Federal. Na área da educação, um marco contributivo para massificação do termo entre os educadores e educadoras foram as polêmicas envolvendo Kit antihomofobia. O material pedagógico apoiado pelo Ministério da Educação e Cultura (MEC), que seria distribuído nas escolas públicas foi popularmente chamado de "kit-gay" e vetado em 2011 pela Presidenta Dilma Roussef, que chegou a afirmar que não seria "[...] permitido a nenhum órgão do governo fazer propaganda de opções sexuais" (O GLOBO, 2011). Em síntese, em todo esse processo podemos notar que o cunho de termos legais como "cidadão homossexual" ou para se referir à diversidade na escola "kit-gay" entre outros, atrelam diretamente a figura exclusiva dos "homossexuais masculinos" como referência de homossexualidade ou sexualidade dissidente e, por conseguinte os centralizam como os alvos principais e preocupantes da violência homofóbica (BRAGA, 2014).
}

mas de assédios velados que, embora não menos graves, por vezes não são consideradas agressões, pelas autoridades escolares. E alertam que essa perspectiva não foi exclusividade de sujeitos heterossexuais, segundo os autores, parte considerável dos jovens gays participantes do estudo também "[...] Mostraram ter visões muito sexistas e por vezes homofóbicas sobre as lésbicas" (tradução nossa). ${ }^{10}$. O que nos leva novamente a afirmar a necessidade de empreender investigações que centralizem as experiências lésbicas, diante da misoginia e sexismo que seguem encobertos em narrativas universais de tolerância à homossexualidade.

No contexto brasileiro, uma pesquisa semelhante à supracitada em termos de abrangência e apropriação por parte dos estudos de gênero e sexualidade na educação é a "Juventudes e Sexualidades" empreendidas por Abramovay, Castro e Silva (2004). A respeito do lesbianismo, as autoras explicam que foi menos evidenciado pelos jovens, pais e profissionais da educação que participaram do estudo em comparação com a sexualidade gay. Entretanto, isso não se configurou como espécie de aceitação e respeito: "[...] há, entre jovens, maior censura e autocensura em relação à homossexualidade feminina, é comum o tratamento depreciativo e por pseudobrincadeiras" seus posicionamentos são "[...] tão estigmatizados, nos discursos, quanto à homossexualidade masculina" (p. 284).

Por fim, para complementar esses dados, que evocamos, apesar de sua distância temporal, devido ao alcance e destaque nos debates acadêmicos, citamos os trabalhos realizados mais recentemente por pesquisadoras como: Cavalero (2009), Oliveira (2010) e Fortes (2013), que também denunciaram as hostilizações e au-

10 "[...] expressed very sexist and sometimes homophobic views of lesbians." 
sência de suporte encontrados em espaços educativos sentidos por garotas nãoheterossexuais.

\section{CONSIDERAÇõES FINAIS}

Para encerrar este texto, pontuamos que os dados sobre as violências e discriminações, bem como a carga conceitual que também perpassa esse aspecto em nosso artigo, foram trazidos aqui no intento de chamar a atenção para a relevância social implicada nos estudos sobre gênero e sexualidade, diante do momento histórico do nosso país, em que se multiplicam discursos políticos conservadores, materiais para promover o respeito às diferenças de sexualidade nas escolas são vetados ${ }^{11}$, o tema de gênero é excluído do Plano Nacional de Educação ${ }^{12}$ e a criminalização da homofobia, proposta há quase uma década e meia, em nível federal, ainda não se efetivou ${ }^{13}$.

Contudo, ressaltamos que também temos o propósito de relativizar os relatos de violência que surgirão no desenrolar da pesquisa, pois as trajetórias escolares das lésbicas, bem como de outros sujeitos não-heterossexuais, ainda que com frequência marcadas por conflitos referentes a sexualidade (JOCA, 2012) não devem ser reduzidas a esse aspecto, que ao ser hipervalorizado, oculta as vivências empo-

${ }^{11}$ Podemos citar como veto, o feito em 2011 ao material pedagógico apoiado pelo Ministério da Educação e Cultura (MEC): "Kit antihomofobia", que seria distribuído nas escolas públicas brasileiras.

${ }^{12}$ A exclusão especifica do gênero foi realizada em 2014 no texto do Plano Nacional de Educação (PNE) e consequentemente retirada de muitos planos municipais e estaduais da educação em 2015.

${ }^{13} \mathrm{~A}$ criminalização da violência homofobia em âmbito nacional foi proposta em 2001, por meio da criação do Projeto de Lei Complementar no 5003/2001. deradoras, prazerosas, potentes, subversivas e resistentes dos sujeitos.

Pensamos que o debate não deve desembocar naquilo que DAYRELL (2007, p.1106) chamou de: "[...] visão apocalíptica sobre o fracasso da instituição escolar" ao abordar os rumos que a discussão sobre os desafios da educação da juventude tem tomado. Ao passarem pelo processo de educação formal, os sujeitos produzem momentos próprios de socialização no ambiente educativo, sociabilidade esta que ressignifica o espaço físico da instituição de ensino (pátio em que ocorre o intervalo, escadas, banheiros, entrada, percurso até a escola entre outros) onde se fortalecem as amizades, afetividades, solidariedades, além de trocas de informações e aprendizagens (DAYRELL, 2007).

\section{REFERÊNCIAS BIBLIOGRÁFICAS:}

BARBOSA, Regina Maria; FACCHINI, Regina. Dossiê saúde das mulheres lésbicas. promoção da equidade e da integralidade. Rede Feminista de Saúde, Belo Horizonte. 2006.

BENTO, Berenice. Na escola se aprende que a diferença faz a diferença. Estudos Feministas, Florianópolis, v. 19, n. 2. 2011, p. 549- 559.

BOCHENEK, Michael; BROWN, Widney. Hatred in the hallways: Violence and discrimination against lesbian, gay, bisexual, and transgender students in U.S. schools. Human Rights Watch, 2001.

BORRILLO, Daniel. Homofobia: Historia e crítica de um preconceito. Belo Horizonte: Autêntica, 2010.

BRAGA, Keith Daiani da Silva. Homofobia na escola: análise do Livro de Ocorrência Escolar. Dissertação (Mestrado em Educação). Presidente Prudente: FCT/UNESP, 2014. 
BRANDÃO, Ana Maria. A gestão do segredo: homo-erotismo feminino e relações familiares e de amizade, LES Online, v. 7, n.1, 2015, p. 03-16.

BRASIL. Ministério da Educação e do Desporto. Brasil Sem Homofobia: Programa de Combate à Violência e à Discriminação contra GLTB e Promoção da Cidadania Homossexual. Secretaria Especial de Direitos Humanos: Ministério da Saúde, 2004.

BRITZMAN, Deborah. O que é esta coisa chamada amor - identidade homossexual, educação e currículo. Revista Educação e Realidade, Porto Alegre, v. 21, n. 1, p. 7196, jan./jun. 1996.

BUTLER, Judith. Problemas de Gênero: feminismo e subversão da identidade. Rio de Janeiro: Civilização Brasileira, 2003 [1990].

CAETANO, Marcio Rodrigo do Vale.Gênero e sexualidade: um encontro político com as epistemologias da vida e os movimentos curriculares. Tese (Doutorado em Educação). Universidade Federal Fluminense, Niterói, 2011.

CASTRO Mary Garcia; ABRAMOVAY Miriam; SILVA Lorena Bernadete. Juventudes e sexualidade. Brasília: UNESCO/ Brasil; 2004.

CAVALERO, Maria Cristina. Feminilidades homossexuais no ambiente escolar: ocultamentos e discriminações vividas por garotas. Tese (Doutorado em Educação), São Paulo: FEUSP, 2009.

CRAWFORD, Charmaine. "It's a Girl Thing" Problematizing Female Sexulity, Gender and Lesbophobia in Caribbean Culture. 2012. Disponível em: <http:// www.caribbeanhomophobias.org/itsagirlthi ng>. Acesso em: 06 Abr. 2015.

DAYRELL, Juarez. A escola "faz" as juven- tudes? Reflexões em torno da socialização juvenil. Educação e Sociedade, Porto Alegre, v. 28 , n. 100 , p. $1105-1128$, out. 2007.

DIAS, Diego Madi. Brincar de gênero, uma conversa com Berenice Bento. Cad. Pagu, Campinas, n. 43, Dec. 2014. p. 475-497.

DINIS, Nilson. O Amor entre Mulheres: A tolerância esconderia mais preconceito?. Revista Latino-americana de Geografia e Gênero, Ponta Grossa, v. 5, n. 1, p. 142 151, jan. / jul. 2014.

ESPINOSA, Yuderkis. Escritos de una lesbiana oscura. Reflexiones críticas sobre feminismo y política de identidad em América Latina, Buenos Aires, Lima, Ed. Em la frontera, 2007.

ESTADO DE SÃO PAULO. Lei Estadual No 10.948. Dispõe sobre as penalidades a serem aplicadas à prática de discriminação em razão de orientação sexual de 05 de Novembro de 2001.

FALQUET, Jules France. Lesbianismo. In: HIRATA, Helena; LABORIE, Françoise; DOARÉ, Helene; SENOTIER, Daniele. Dicionário Crítico do feminismo. São Paulo, Editora UNESP, 2009. p. 122-128.

FORTES, Ana Carolina Magalhães. $A$ escola e a educação não-escolar: experiências da mulher lésbica afrodescendente. Dissertação (Mestrado em Educação). Teresina: Universidade Federal do Piauí, 2013.

GIMENO, Beatriz. La doble marginación de las lesbianas. In: SIMONIS, Angie (Org). Cultura, homosexualidad y homofobia, vol. II, Amazonia, retos de visibilidad lesbiana, Laertes, Barcelona, 2007. [KINDLE EDITION, 2010]

GUILLEMAUT, Françoise. Images invisibles: les lesbiennes. In WELZER-LANG, Daniel; DUTEY, Pierre; DORAIS, Michel. (Org.). La Peur de l'autre en soi, du 
sexisme à I'homophobie. Montréal/Canadá: VLB Éditeur, 1994.

HALBERSTAM, Jack. Masculinidad Femenina. Trad. Javier Sáez, Barcelona-Madrid: E. Egales, 2008.

JOCA, Alexandre Martins. Educação, juventudes e homossexualidades: extratos da sociabilidade de jovens gays em escolas públicas de Fortaleza. Seminário Internacional Fazendo Gênero 10, Anais Eletrônicos, Florianópolis, 2012, p. 1-12.

JUNQUEIRA, Rogério Diniz. Pedagogia do armário e currículo em ação: heteronormatividade, heterossexismo e homofobia no cotidiano escolar. In: MISKOLCI, Richard; PELÚCIO. Larissa (Org.). Discursos fora da ordem: sexualidades, saberes e direitos. São Paulo: Annablume, 2012, p. 277-305.

LAURETIS, Teresa. A tecnologia de gênero. In: HOLLANDA, Heloisa (Org.). Tendências e impasses: o feminismo como crítica da cultura. Rio de Janeiro: Rocco, 1994. p. 206-242.

MACIEL, Patrícia; GARCIA, Maria Manuela Alves. Os femininos no magistério: professoras lésbicas nas escolas. Currículo sem Fronteiras, v. 14 , n. 3, p. $160-180$, set/dez 2014.

O GLOBO. Dilma diz que 'não vai ser permitido a nenhum órgão do governo fazer propaganda de opções sexuais'. 26 de Maio de 2011. Disponível em: < http://oglobo.globo.com/politica/dil ma-diz-que-nao-vai-ser-permitidonenhum-orgao-do-governo-fazerpropaganda-de-opcoes-sexuais-2765417>. Acesso em: 12 Jan 2014.

OLIVEIRA, Lisis Fernandes Brito. A mulher e o poder da heteronormatividade: uma discussão no contexto escolar. Dissertação (Mestrado em Educação). Duque de Caxias: Universidade do Estado do Rio de Ja- neiro, 2010.

PERROT, Michelle. História (sexuação da). InHIRATA, Helena; LABORIE, Françoise; DOARÉ, Helene; SENOTIER, Daniele. Dicionário Crítico do feminismo. São Paulo, Ed. UNESP, 2009. p. 111-116.

PLATERO, Raquel Lucas. Entre la invisibilidad y la igualdad formal: perspectivas feministas ante la representación del lesbianismo en el matrimonio homosexual. In: SIMONIS, Angie (Org.), Cultura, homosexualidad $y$ homofobia, vol. II, Amazonia, retos de visibilidad lesbiana, Laertes, Barcelona, 2007. [KINDLE EDITION, 2010]

PLATERO, Raquel Lucas. La masculinidad de las biomujeres: marimachos, chicazos, camioneras y otras disidentes. 2009a. Disponível em: <http://www.feministas.org/IMG/pdf/La_ masculini-

dad_de_las_biomujeresPlatero.pdf > .

Acesso em: 02 fev. 2015.

PLATERO, Raquel Lucas. Lesboerotismo y la masculinidad de las mujeres en la España franquista. Bagoas, n. 3, 2009b. p. 1538.

RASINES, Paloma Fernández. Homoerotismo entre mujeres y la búsqueda del reconocimiento. In: SIMONIS, Angie (Org.), Cultura, homosexualidad y homofobia, vol. II, Amazonia, retos de visibilidad lesbiana, Laertes, Barcelona, 2007. [KINDLE EDITION, 2010]

RICH, Adrienne. Heterossexualidade compulsória e existência lésbica, Bagoas, v. 4, n. 5, 2010 [1980]. p. 17-44.

RUBIN, Gayle. Reflexionando sobre el sexo: notas para una teoría radical de la sexualidad. In: VANCE, C. (Org.). Placer y peligro: explorando la sexualidad femenina. Madrid: Revolución Madrid, 1989. p. 113-190. 
SWAIN, Tania Navarro. O que é lesbianismo. São Paulo: Brasiliense, 2000.

TOLEDO, Lívia Gonçalves. Estigmas e estereótipos sobre as lesbianidades e suas influências nas narrativas de histórias de vida de lésbicas residentes em uma cidade do interior paulista. Dissertação (Mestrado em Psicologia). Assis: Universidade Estadual Paulista, 2008.

VIÑUALES, Olga. Lesbofobia, Bellaterra, Barcelona, 2002.

WILTON, Tamsin. Lesbian Studies. Setting an agenda, London, Routledge, 1995. [KINDLE EDITION, 2003]

WITTIG, Monique. El pensamento heterosexual. In.: WITTIG, Monique. El pensamiento heterosexual y otros ensayos. Barcelona/Madrid: Editora Egales, 2006 [1980]. 